\title{
Comparing results of $\mathrm{X}$-ray diffraction, $\mu$-Raman spectroscopy and neutron diffraction when identifying chemical phases in seized nuclear material, during a comparative nuclear forensics exercise
}

\author{
Stina Holmgren Rondahl ${ }^{1} \cdot$ Fabien Pointurier $^{2} \cdot$ Linnea Ahlinder $^{1} \cdot$ Henrik Ramebäck $^{1,3} \cdot$ Olivier Marie $^{2}$. \\ Brice Ravat ${ }^{4} \cdot$ François Delaunay $^{4} \cdot$ Emma Young $^{5} \cdot$ Ned Blagojevic $^{5} \cdot$ James R. Hester $^{5} \cdot$ Gordon Thorogood $^{5}$. \\ Aubrey N. Nelwamondo ${ }^{6} \cdot$ Tshepo P. Ntsoane $^{6} \cdot$ Sarah K. Roberts $^{7} \cdot$ Kiel S. Holliday $^{7}$
}

Received: 15 December 2017 / Published online: 24 January 2018

(C) The Author(s) 2018. This article is an open access publication

\begin{abstract}
This work presents the results for identification of chemical phases obtained by several laboratories as a part of an international nuclear forensic round-robin exercise. In this work powder X-ray diffraction (p-XRD) is regarded as the reference technique. Neutron diffraction produced a superior high-angle diffraction pattern relative to $\mathrm{p}$-XRD. Requiring only small amounts of sample, $\mu$-Raman spectroscopy was used for the first time in this context as a potentially complementary technique to p-XRD. The chemical phases were identified as pure $\mathrm{UO}_{2}$ in two materials, and as a mixture of $\mathrm{UO}_{2}, \mathrm{U}_{3} \mathrm{O}_{8}$ and an intermediate species $\mathrm{U}_{3} \mathrm{O}_{7}$ in the third material.
\end{abstract}

Keywords XRD · $\mu$-Raman Spectroscopy · Neutron diffraction · Phase identification · Nuclear forensics · Uranium oxide

Electronic supplementary material The online version of this article (https://doi.org/10.1007/s10967-017-5666-3) contains supplementary material, which is available to authorized users.

Stina Holmgren Rondahl

stina.holmgren@foi.se

1 CBRN Defence and Security, Swedish Defence Research Agency (FOI), Umeå, Sweden

2 DAM, DIF, French Alternative Energies and Atomic Energy Commission (CEA), 91297 Arpajon, France

3 Department of Chemistry and Chemical Engineering, Nuclear Chemistry, Chalmers University of Technology, Göteborg, Sweden

4 French Alternative Energies and Atomic Energy Commission (CEA), CEA-Centre de Valduc, 21120 Is-Sur-Tille, France

5 Australian Nuclear Science and Technology Organisation (ANSTO), New Illawarra Road, Lucas Heights, NSW 2234, Australia

6 South Africa Nuclear Energy Corporation (NECSA) Pelindaba, 582, Pretoria 0001, Gauteng, South Africa

7 Lawrence Livermore National Laboratory (LLNL), Livermore, CA 94551, USA

\section{Introduction}

The fourth collaborative material exercise (CMX-4) organized by the Nuclear Forensics International Technical Working Group (ITWG) comprised a scenario where two samples had been confiscated after an alleged "simple possession" of a radioactive nature. A black powder (ES1), approximately $3 \mathrm{~g}$ of sample, was found on a suspect at an international airport, and an item suspected to be a nuclear fuel pellet (ES-2) was subsequently found in a shed at the housing of the suspected person. Two years prior to these seizures another fuel pellet (ES-3) was seized by authorities at an abandoned warehouse in another country. More details about this exercise can be found in Ref. [1]. This includes the description of several other techniques for identification of physical and chemical characteristics of the seized materials, like isotopic composition, elemental composition, and date of the last separation. The results from all of these techniques were used to draw conclusions regarding similarities between, and the possible origin of, the three samples.

Reports were to be submitted to the exercise coordinators after $24 \mathrm{~h}, 1$ week and 2 months after receipt of the 
samples. These timelines are in accordance with the IAEA Nuclear security recommendations [2].

Identifying the phases of the seized materials aids in pinpointing the origin of the materials (e.g., type of nuclear facility used for the production or handling of seized materials). A few laboratories that participated in the exercise used $\mu$-Raman spectroscopy ( $\mu$-RS) and/or powder $\mathrm{X}$-ray diffraction ( $\mathrm{p}$-XRD) for phase identification. One laboratory used neutron diffraction (ND) to identify the chemical phases in the powder sample (ES-1).

The techniques, $\mu$-RS, $\mathrm{p}$-XRD, and ND are all quick and easy to implement since they require a minimum of sample preparation. Moreover, $\mu-\mathrm{RS}$ is very sensitive to slight changes on molecular environment and crystalline phase, as it is possible to simultaneously measure Raman active phonon modes in crystalline materials and Raman active vibrational modes in molecules. It is thus possible to both get a unique spectral fingerprint of different polymorphs of crystalline materials and spectral information from molecules in the measurement spot. Besides, all three techniques are practically nondestructive, even for microscopic objects. In the case of $\mu$-RS care must be taken not to induce laser damage. Also, $\mu$-RS has the specific advantage of being applicable to very small sample amounts $(\mu \mathrm{m}$ sized particles), and in case of heterogeneous samples can be used to analyze micrometric details of the materials (e.g., some parts of the sample which differ in color or aspect compared to the main part of the material). In the past $\mu$-RS was successfully applied to identify the main uranium compounds encountered in the nuclear industry [3-14]. Powder XRD is known to be an efficient tool for the phase analysis of nuclear compounds, although higher amounts of material are necessary as compared to $\mu$-RS. A typical p-XRD pattern consists of a set of diffraction peaks of intensity $I$ (in counts) located at reflective angles $2 \theta$ (in degrees) corresponding to lattice plane spacing, or reciprocal lattice vector $d_{h, k, l}$, of crystallographic indices $(h, k, l)$ as given by Bragg's law:

$n \lambda=2 d_{h, k, l} \sin (\theta)$

where $\lambda$ is the wavelength of the X-ray source (in $\AA$ ) and $n$ is a positive integer. This allows for identification of phase and relative composition (structural characterization) by matching the measured peaks at, in particular, $2 \theta$ in terms of the peak position and intensity with the patterns from the International Centre for Diffraction Data (ICDD), Crystallography Open Database (COD) or similar libraries [15-17]. To evaluate all sample diffraction patterns collected by $\mathrm{p}$-XRD for the four laboratories the raw data [i.e., collected relative intensities at different angles (20)] was converted from $2 \theta$ to $d_{\mathrm{h}, \mathrm{k}, 1}$ according to Eq. (1). Powder XRD was earlier used to ascertain the phases measured by $\mu$-RS when bibliographic information was limited
$[9,13,18,19]$. ND provides complementary information to p-XRD because neutrons interact with the point-like nucleus of an atom, whereas X-rays interact with the extended electron cloud surrounding the atom. The neutron interaction is not proportional to $\mathrm{Z}$, so low $\mathrm{Z}$ atoms (such as oxygen) contribute significantly to the diffracted intensity in ND, whereas the diffracted intensity in $\mathrm{p}$-XRD is dominated by the higher $\mathrm{Z}$ atoms (such as uranium). Furthermore, the point scattering of the neutron results in a much slower drop-off in intensity at high angles.

The aim of this paper is to show how $\mu$-RS can be used to complement XRD, or in the absence of XRD when differentiating between the three materials used during CMX-4. In this paper results obtained by $\mu$-RS will be presented and compared to the result obtained by $\mathrm{p}$-XRD and $\mathrm{ND}$, as the latter two are more established methods with a greater reference library. The instruments and methods used for phase identification of the three materials, and the results obtained with these techniques, will be presented, compared, and discussed. Specific concerns like homogeneity of the samples at the micrometer-scale and possible oxidization of the samples by the RS laser will be addressed.

\section{Instruments and methods}

\section{Instruments}

Main characteristics of the instruments; p-XRD used by laboratories (code-named) Vermeer, Pollock, Rembrandt, Cezanne, and Monet; $\mu$-RS used by Vermeer and Pollock; and Echidna high-resolution powder neutron diffractometer (ND) used by Rembrandt [20] are presented in Tables 1, 2, 3.

It should be mentioned that the RS used by Pollock and Vermeer are $\mu$-RS, for which the laser beam is focused though an optical microscope. Consequently, very small areas $\left(\sim 1 \mu \mathrm{m}^{2}\right)$ are analyzed. At the Vermeer laboratory, the $\mu$-RS equipped with a true confocal aperture allows spatially resolved measurements over a couple of $\mu \mathrm{m}$ along the lateral (depth) axis.

\section{Sample preparations and analytical procedures}

The sample preparation and analytical conditions applied for XRD analyses are summarized in Table 4.

Sample preparation and analytical conditions applied for $\mu$-RS analyses are summarized in Table 5. For Pollock, it should be noted that only very low amounts of uranium can be handled in the laboratory and inside the instrument, dedicated to trace analysis of nuclear materials. Therefore, only small fragments (typically tens of $\mu \mathrm{m}$ ), although 
Table 1 Characteristics of the five XRD instruments used in this study

\begin{tabular}{|c|c|c|c|c|c|}
\hline Laboratory & Vermeer & Pollock & Rembrandt & Cezanne & Monet \\
\hline $\begin{array}{l}\text { Manufacturer and } \\
\text { model }\end{array}$ & Bruker D2 phaser & Bruker D8 advance & $\begin{array}{c}\text { Bruker D8 } \\
\text { advance }\end{array}$ & Bruker D8 advance & Bruker D8 advance \\
\hline $\begin{array}{l}\text { Source and } \\
\text { wavelength }^{\mathrm{a}}\end{array}$ & $\begin{array}{l}\mathrm{Cu} \mathrm{X} \text { ray tube } \\
k_{\alpha 1}: \lambda=1.54060 \AA\end{array}$ & $\begin{array}{l}\text { Mo X ray tube } \\
k_{\alpha 1}: \lambda=0.7093 \AA \\
k_{\alpha 2}: \\
\lambda=0.71359 \AA\end{array}$ & $\begin{array}{l}\mathrm{Cu} X \text { ray tube } \\
k_{\alpha 1}: \\
\lambda=1.540564 \AA \\
k_{\alpha 2}: \\
\lambda=1.544390 \AA\end{array}$ & $\begin{array}{l}\mathrm{Cu} \mathrm{X} \text { ray tube } \\
k_{\alpha 1}: \lambda=1.54060 \AA\end{array}$ & $\begin{array}{l}\mathrm{Cu} X \text { ray tube } \\
k_{\alpha 1}=1.540598 \AA\end{array}$ \\
\hline $\begin{array}{l}\text { Device for } \\
\text { reduction of the } \\
k_{\beta} \text {-peaks }\end{array}$ & $\mathrm{Ni}$-foil & Zr-foil & $\mathrm{N} / \mathrm{A}^{\mathrm{b}}$ & $\mathrm{Ni}$-foil & Ni-foil \\
\hline $\begin{array}{l}\text { Goniometer radius } \\
\theta / \theta(\mathrm{mm})\end{array}$ & 282.2 & 250 & 173 & 217.5 & 300 \\
\hline Detector & $\begin{array}{l}\text { 1-dimensional Lynx } \\
\text { Eye, PSD detector } \\
\text { Angular aperture: } 5^{\circ} \\
\text { (fixed) }\end{array}$ & $\begin{array}{l}\text { 1-dimensional } \\
\text { Vantec, PSD } \\
\text { detector } \\
\text { Angular aperture: } \\
6^{\circ}\end{array}$ & $\begin{array}{l}\text { LynxEye } \mathrm{XE}^{\mathrm{b}} \\
\text { Angular aperture: } \\
3.0^{\circ}\end{array}$ & $\begin{array}{l}\text { 1-dimensional Lynx Eye, PSD } \\
\text { detector Angular aperture: } 2.7^{\circ}\end{array}$ & $\begin{array}{l}\text { 1-dimensional Lynx } \\
\text { Eye, PSD detector } \\
\text { Angular aperture: } \\
2.7^{\circ}\end{array}$ \\
\hline Geometry & $\begin{array}{l}\text { Bragg-brentano } \\
\theta / \theta\end{array}$ & $\begin{array}{l}\text { Bragg-brentano } \\
\theta / \theta\end{array}$ & $\begin{array}{l}\text { Bragg-brentano } \\
\theta / \theta\end{array}$ & $\begin{array}{l}\text { Bragg-brentano } \\
\theta / \theta\end{array}$ & $\begin{array}{l}\text { Bragg-brentano } \\
\theta / \theta\end{array}$ \\
\hline Primary slits & $0.2 \mathrm{~mm}$ & $0.2 \mathrm{~mm}$ & $1 \mathrm{~mm}, 1.2^{\circ}, 1 \mathrm{~mm}$ & $0.2 \mathrm{~mm}$ & $0.1 \mathrm{~mm}$ \\
\hline
\end{tabular}

${ }^{a}$ Emission profile validated by measurements on a certified reference material produced by Bruker, the corundum sample, or NIST SRM 1976 [21]

${ }^{\mathrm{b}}$ Energy discriminating detector, no need for secondary monochromator or metal filters

Table 2 Characteristics of the neutron diffractometer used in this study

\begin{tabular}{ll}
\hline Laboratory & Rembrandt \\
\hline Manufacturer and model & Echidna high-resolution powder diffractometer \\
Wavelength & $1.622 \AA$ \\
$d$-spacing range & $0.8-14 \AA$ \\
Sample tube & Vanadium cylinder \\
& $6 \mathrm{~mm}$ diameter \\
Detector and operating temperature $\left({ }^{\circ} \mathrm{C}\right)$ & $0.1 \mathrm{~mm}$ thick \\
\hline
\end{tabular}

regarded as macroscopic pieces, of the two original pellets were sampled and analyzed at Pollock. Pollock also analyzed micrometric particles directly sampled onto the pellets, before breaking them in several parts. The goal of these complementary analyses was to check for other possible chemical compositions than the one determined for the pellets (i.e., another uranium compound handled in the original nuclear facility that had been produced by a nuclear activity other than the one which led to pellet manufacturing). A special preparation procedure was used for these samples: sampling with cotton wipes swiped onto surfaces of the pellets, deposition onto graphite disk using a vacuum impactor, which aspires particles and deposits them onto a glassy carbon disk. Eventually, uranium particles were located at the disk's surface by SEM and relocated inside the $\mu$-RS using a mathematical calculation.

Pollock and Vermeer both carried out uncertainty calculations on the positions of the Raman bands. Uncertainties are the quadratic combination of a systematic uncertainty of $0.5 \mathrm{~cm}^{-1}$ (estimated from repetitive measurements of the main band of silicon at $520.5 \mathrm{~cm}^{-1}$ ) and of the standard deviation calculated over all measurements (20 per sample). If not stated otherwise, all uncertainties are expanded uncertainties with a coverage factor $k=2$, corresponding to an approximate 95 percent confidence interval.

No sample pretreatment was required for ND analysis of the powder. Approximately $1.7 \mathrm{~g}$ of the powder, as 
Table 3 Characteristics of the two $\mu$-Raman spectrometers used in this study

\begin{tabular}{|c|c|c|}
\hline Laboratory & Vermeer & Pollock \\
\hline Manufacturer and model & Horiba-Jobin-Yvon HR 800 UV & Renishaw 'Invia' \\
\hline \multirow[t]{2}{*}{ Laser wavelength (nm) } & 514 & 514 \\
\hline & 785 & 785 \\
\hline \multirow{2}{*}{$\begin{array}{l}\text { Laser characteristics (lasing } \\
\text { medium) }\end{array}$} & Argon ion $(514 \mathrm{~nm})$ & Argon ion $(514 \mathrm{~nm})$ \\
\hline & Diode semi-conductor $(785 \mathrm{~nm})$ & $\begin{array}{l}\text { Diode semi-conductor } \\
\quad(785 \mathrm{~nm})\end{array}$ \\
\hline Spot size of laser & With $\times 100$ objective: $\sim 0.4 \mu \mathrm{m}^{2}$ & $\begin{array}{l}\text { With } \times 100 \\
\text { objective: } \sim 0.4 \mu \mathrm{m}^{2}\end{array}$ \\
\hline \multirow[t]{5}{*}{ Gratings (lines/mm) } & 300 for $785 \mathrm{~nm}$ & 1800 for $514 \mathrm{~nm}$ \\
\hline & 600 for $785 \mathrm{~nm}$ & 1200 for $785 \mathrm{~nm}$ \\
\hline & 1200 for $785 \mathrm{~nm}$ & \\
\hline & 600 for $514 \mathrm{~nm}$ & \\
\hline & 1800 for $514 \mathrm{~nm}$ & \\
\hline \multirow[t]{3}{*}{ Spectral range $\left(\mathrm{cm}^{-1}\right)$} & $>4000$ (for 1800 lines $/ \mathrm{mm})$ & $>4000(514 \mathrm{~nm})$ \\
\hline & Up to $\sim 3500$ (for 600 lines $/ \mathrm{mm})$ & Up to $\sim 3200(785 \mathrm{~nm})$ \\
\hline & Up to $\sim 1700$ (for 300 lines $/ \mathrm{mm})$ & \\
\hline $\begin{array}{l}\text { Focal distance of the spectrometer } \\
(\mathrm{cm})\end{array}$ & 80 & 25 \\
\hline \multirow[t]{6}{*}{ Numerical aperture (NA) } & 0.25 for $\times 10$ & 0.75 for $\times 50$ \\
\hline & 0.45 for $\times 50$ long work distance & 0.85 for $\times 100$ \\
\hline & 0.75 for $\times 50$ & \\
\hline & 0.9 for $\times 60$ water immersion & \\
\hline & 0.9 for $\times 100$ & \\
\hline & 1.25 for $\times 100$ oil immersion & \\
\hline \multirow[t]{2}{*}{ Output power $(\mathrm{mW})$} & $300(785 \mathrm{~nm})$ & $300(785 \mathrm{~nm})$ \\
\hline & $50(514 \mathrm{~nm})$ & $50(514 \mathrm{~nm})$ \\
\hline Slit $(\mu \mathrm{m})$ & $\mathrm{N} / \mathrm{A}^{\mathrm{a}}$ & Motorized, from 20 to $65 \mu \mathrm{m}$ \\
\hline $\begin{array}{l}\text { Detector and operating } \\
\text { temperature }\left({ }^{\circ} \mathrm{C}\right)\end{array}$ & Peltier (air) cooled $\mathrm{CCD}\left(-70^{\circ} \mathrm{C}\right)$ & $\begin{array}{l}\text { Peltier (air) cooled } \\
\operatorname{CCD}\left(-70^{\circ} \mathrm{C}\right)\end{array}$ \\
\hline Typical integration time (range) & $10 \mathrm{~ms}$ to infinity & $10 \mathrm{~ms}$ to infinity \\
\hline Objectives & $\begin{array}{l}\times 10, \times 50, \times 50 \text { long work distance, } \times 60 \text { water immersion, } \times 100, \times 100 \\
\text { oil immersion }\end{array}$ & $\times 5, \times 20, \times 50, \times 100$ \\
\hline
\end{tabular}

${ }^{a}$ No slit, since the instrument is a true confocal microscope and a confocal hole is used to control the sampling volume

received, was loaded into a cylindrical vanadium can (6 $\mathrm{mm}$ diameter and $0.1 \mathrm{~mm}$ wall thickness), where it was fully illuminated by a $50 \mathrm{~mm}(\mathrm{~V}) \times 20 \mathrm{~mm}(\mathrm{~W})$ neutron beam. No sample rotation was required, as the combination of moderate beam divergence, high sample transparency, and relatively large quantity of sample ensured that a statistically large number of powder domains were in the diffracting condition at any given position.

\section{Results and discussion}

\section{Results of the phase analysis of the pellet samples}

\section{$p$-XRD results for the two pellets}

XRD pattern obtained for the two pellet samples (ES-2 and ES-3) by the five laboratories are given in Fig. 1. The diffraction patterns for these samples are very similar when comparing the results from all laboratories. Also, the diffraction peaks are very thin, which implies long-range ordering of the two materials. All laboratories observed a good match with the expected peak positions for $\mathrm{UO}_{2}$ 
Table 4 Sample treatment and analytical data handling for XRD analyses

\begin{tabular}{|c|c|c|c|c|c|}
\hline Laboratory & Vermeer & Pollock & Rembrandt & Cezanne & Monet \\
\hline $\begin{array}{l}\text { Sample } \\
\text { holder }\end{array}$ & $\begin{array}{r}\text { Bruker (PMMA) } \\
\text { holders, rotated } \\
\text { during analysis }\end{array}$ & $\begin{array}{l}\text { Anton Paar - } \\
\text { TTK } 450 \\
\text { chamber, not } \\
\text { rotated during } \\
\text { analysis }\end{array}$ & $\begin{array}{l}\text { Bruker Airtight }{ }^{\mathrm{a}} \text { holder } \\
\text { (PMMA) with dome-type } \\
\text { X-ray transparent cap, rotated } \\
\text { during analysis }\end{array}$ & $\begin{array}{l}\text { Bruker Airtight }{ }^{\text {a }} \text { holder } \\
\text { (PMMA) with dome- } \\
\text { type X-ray transparent } \\
\text { cap, not rotated during } \\
\text { analysis }\end{array}$ & $\begin{array}{l}\text { Bruker (PMMA) } \\
\text { holders. Pellets } \\
\text { rotated during } \\
\text { analysis, powders } \\
\text { not rotated during } \\
\text { analysis }\end{array}$ \\
\hline $\begin{array}{l}\text { CMX-4 } \\
\text { sample } \\
\text { pre- } \\
\text { treatment }\end{array}$ & $\begin{array}{l}\text { A subsample of ES-1 } \\
\text { powder loaded into } \\
\text { shallow plastic } \\
\text { holder. ES-2 \& ES-3 } \\
\text { were measured as } \\
\text { pellets. }\end{array}$ & $\begin{array}{l}\text { ES-1 powder } \\
\text { loaded } \\
\text { between two } \\
\text { sealed Kapton } \\
\text { sheets } \\
\text { ES-2 \& ES-3 } \\
\text { were } \\
\text { measured as } \\
\text { pellets. }\end{array}$ & $\begin{array}{l}\text { Samples were mounted in } \\
\text { airtight specimen holders with } \\
\text { a plastic dome cover. ES-1 } \\
\text { was analyzed as received. ES- } \\
2 \text { and ES-3 were analyzed as } \\
\text { resin-mounted sub-samples of } \\
\text { the two pellets. }\end{array}$ & $\begin{array}{l}\text { ES-1 powder loaded into } \\
\text { holder as received. ES- } \\
2 \text { \& ES-3 pellets first } \\
\text { ground to powder to } \\
\text { homogenous sample }\end{array}$ & $\begin{array}{l}\text { ES-1, ES-2 and ES-3; } \\
\text { analysed as } \\
\text { received. } \\
\text { Subsamples from } \\
\text { pellets were ground } \\
\text { into powders }\end{array}$ \\
\hline $\begin{array}{c}\text { Evaluation } \\
\text { package }\end{array}$ & $\begin{array}{l}\text { Proprietary EVA } \\
\text { Software and PDF-2 } \\
\text { reference database } \\
2015 \text { (ICDD) }\end{array}$ & $\begin{array}{l}\text { Proprietary } \\
\text { EVA Software } \\
\text { and PDF- } \\
4+\text { reference } \\
\text { database } \\
\text { (ICDD) }\end{array}$ & $\begin{array}{l}\text { X'Pert HighScore search/match } \\
\text { data analysis software and } \\
\text { PDF-2 reference database }\end{array}$ & $\begin{array}{l}\text { Proprietary EVA } \\
\text { Software and PDF-2 } \\
\text { reference database } \\
2007 \text { (ICDD) }\end{array}$ & $\begin{array}{l}\text { Proprietary EVA and } \\
\text { TOPAS Software } \\
\text { and PDF-2 database } \\
2009 \text { (ICDD) }\end{array}$ \\
\hline $\begin{array}{l}d \text { spacing } \\
\text { analysis } \\
\text { range }\end{array}$ & $4.4-1.2$ & $4.2-0.85$ & $17-0.80$ & $5.9-0.89$ & $\begin{array}{l}17-1.3 \text { for solid } \\
\text { pellets and } 8.8-1.4 \\
\text { for powder samples }\end{array}$ \\
\hline $\begin{array}{l}\text { Acquisition } \\
\text { time (min) }\end{array}$ & $\begin{array}{l}42 \\
\left(2500 \text { steps, } 0.024^{\circ}\right. \\
\text { step size, } 1 \text { steps/s) }\end{array}$ & $\begin{array}{l}900 \\
(2700 \text { steps, } \\
0.015^{\circ} \text { step } \\
\text { size, } 0.05 \\
\text { steps/s) }\end{array}$ & $\begin{array}{l}480 \\
\left(2900 \text { steps, } 0.05^{\circ} \text { step size, } 0.1\right. \\
\text { steps/s) }\end{array}$ & $\begin{array}{l}460 \\
\left(11,040 \text { steps, } 0.001^{\circ}\right. \\
\quad \text { step size, } 0.4 \text { steps/s })\end{array}$ & $\begin{array}{l}\text { Solids: } 126(3648 \\
\text { steps, } 0.01,918^{\circ} \\
\text { step size, } 0.5 \text { steps/ } \\
\text { s) } \\
\text { Powders: } 109(3128 \\
\text { steps, } 0.01918^{\circ} \\
\text { step, } 0.5 \text { steps/s })\end{array}$ \\
\hline $\begin{array}{l}\text { XRD } \\
\text { pattern } \\
\text { refinement }\end{array}$ & $\begin{array}{l}\text { Bruker EVA for semi- } \\
\text { quantitative phase } \\
\text { analysis, RIR method }\end{array}$ & $\begin{array}{l}\text { Bruker EVA for } \\
\text { semi- } \\
\text { quantitative } \\
\text { phase analysis, } \\
\text { RIR method }\end{array}$ & GSAS-II $^{\mathrm{b}}$ freeware & $\begin{array}{l}\text { Bruker EVA for semi- } \\
\text { quantitative phase } \\
\text { analysis, RIR method }\end{array}$ & $\begin{array}{l}\text { Bruker EVA for } \\
\text { semi-quantitative } \\
\text { phase analysis, } \\
\text { Bruker TOPAS }{ }^{\mathrm{c}} \text { for } \\
\text { quantitative phase } \\
\text { analysis }\end{array}$ \\
\hline
\end{tabular}

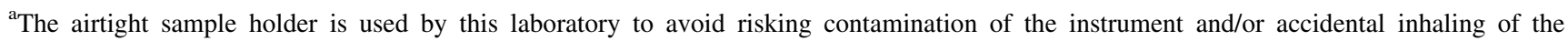
radioactive material

${ }^{\mathrm{b}}$ General structure analysis system-II crystal structure refinement

${ }^{\mathrm{c}}$ Total pattern analysis solutions-software

centered-face cubic crystal phase (card PDF number 03-065-0285 [23]), indicating that both ES-2 and ES-3 are made of pure $\mathrm{UO}_{2}$, with a lattice parameter of $5.4710 \AA$.

No significant difference could be established between the ES-2 and ES-3 phases based on their p-XRD pattern, except for the diffraction pattern for ES-3 from Monet. A non-stoichiometric $\mathrm{UO}_{2}+x(x=0.25)$ was identified with its main peak at d-spacing $3.12 \AA$. The additional phase in ES-3 is thought to be due to aging on the surface of the pellet, which would result in an oxidized phase. When analyzing a crushed and powdered sub-sample of ES-3 there was no non-stoichiometric $\mathrm{UO}_{2}$ phase to be found.

All diffraction patterns, except the ones from Cezanne, observe double peaks throughout. These double peaks are $k_{\alpha, 2}$ peaks from the X-ray source. They can be removed by the evaluation software. However, at $d$ spacing 1.8, 2.6, and $3.0 \AA$, small peaks are visible for Cezanne. As those peaks are thought to result from the sample preparation, their phase identification was not performed. These peaks are not observed for any of the other four laboratories. 
Table 5 Sample preparation techniques and analytical conditions for RS analyses

\begin{tabular}{|c|c|c|c|}
\hline Laboratory & Vermeer & Pollock macroscopic fragments & Pollock surface micrometric particles \\
\hline $\begin{array}{l}\text { Sub-sampling } \\
\text { and } \\
\text { preparation }\end{array}$ & $\begin{array}{l}\text { ES-3: one fragment }(\sim 0.5 \mathrm{~g}) \\
\text { after broken up into } 4 \text { pieces } \\
\text { ES-2: entire pellet } \\
\text { ES-1: transfer of } \sim 0.01 \mathrm{~g} \text { to a } \\
\text { substrate using a } 1 \mathrm{ml} \text { pipette } \\
\text { tip }\end{array}$ & $\begin{array}{l}\text { ES-2 and ES-3: several fragments } \\
(\sim 10-100 \mu \mathrm{m}) \text { after breaking } \\
\text { pellets sampled with sticky carbon } \\
\text { tape } \\
\text { ES-1: small tip in contact with the } \\
\text { powder, then with a sticky carbon } \\
\text { tape }\end{array}$ & $\begin{array}{l}\text { ES-2 and ES-3: gently wiping surfaces of the } \\
\text { pellets with cotton clothes. Extraction from } \\
\text { cotton, deposition onto graphite disk, SEM } \\
\text { localization }\end{array}$ \\
\hline Substrate & $\begin{array}{l}\mathrm{CaF}_{2} \text { substrate for ES-1, ES-2 } \\
\text { and ES-3 were measured } \\
\text { directly on a glass plate }\end{array}$ & Sticky carbon tapes & Graphite disk \\
\hline $\begin{array}{l}\text { Laser used for } \\
\text { the analysis } \\
(\mathrm{nm})\end{array}$ & 514 & 514 & 514 \\
\hline Power (mW) & $\begin{array}{l}\text { Six for all samples } \\
13 \text { for time study of ES- } 3^{b}\end{array}$ & $\sim 2.5(5 \%)^{\mathrm{b}}$ & $\begin{array}{l}\sim 0.05(0.1 \%)^{\mathrm{b}}, \sim 0.5(1 \%)^{\mathrm{b}} \text { or } \sim 2.5(5 \%)^{\mathrm{b}} \\
\text { depending on the particle size }\end{array}$ \\
\hline $\begin{array}{l}\text { Acquisition } \\
\text { time (s) }\end{array}$ & $\begin{array}{l}60 \\
30 \times 60 \text { at the same spot for ES-2 } \\
\text { to evaluate possible oxidation } \\
\text { caused by the laser irradiation }\end{array}$ & $60(6 \times 10)$ & $60(6 \times 10)$ \\
\hline $\begin{array}{l}\text { Number of } \\
\text { measurements }\end{array}$ & 20 each sample & 20 each sample & $\begin{array}{l}20 \text { particles for ES-2 } \\
20 \text { particles for ES-3 }\end{array}$ \\
\hline $\begin{array}{l}\text { Spectral range } \\
\left(\mathrm{cm}^{-1}\right)\end{array}$ & $200-1800^{\mathrm{a}}$ & $100-1400^{\mathrm{a}}$ & $100-1400^{\mathrm{a}}$ \\
\hline Objective & $\begin{array}{l}\times 10 \text { for ES- } 2 \text { and ES-3 } \\
\times 50 \text { for ES- } 1\end{array}$ & $\times 100$ & $\times 100$ \\
\hline $\begin{array}{l}\text { Background } \\
\text { correction } \\
\text { (Yes/No), } \\
\text { method }\end{array}$ & $\begin{array}{l}\text { Yes, background correction } \\
\text { according to Zhang et al. [22] }\end{array}$ & $\begin{array}{l}\text { Yes, cubic spline interpolation } \\
\text { provided with Wire 3.4. software } \\
\text { package }\end{array}$ & Yes, cubic spline interpolation \\
\hline $\begin{array}{l}\text { Curve fitting } \\
\text { (Yes/No), } \\
\text { algorithm }\end{array}$ & $\begin{array}{l}\text { Yes, provided with LabSpec } 6 \\
\text { software }\end{array}$ & $\begin{array}{l}\text { Yes, provided with Wire } 3.4 \\
\text { software package }\end{array}$ & Yes, provided with Wire 3.4 software package \\
\hline
\end{tabular}

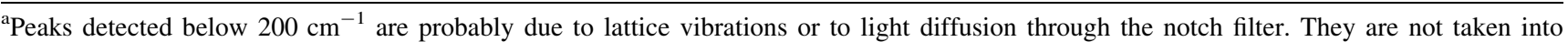
account in data treatment

${ }^{\mathrm{b}}$ Incident powers of the RS are adjusted thanks to attenuation filters, which allow transmission of a given percentage of the maximal power

Worth noting is that the intensity observed, in the diffraction pattern obtained for Pollock, differ from the other four laboratories due to their use of Mo X-ray source instead of $\mathrm{Cu}$. However, this is not a problem seeing as the work presented focuses on identification rather than quantitative analysis, where peak intensity would have an impact.

\section{RS results for ES-2 and ES-3 pellets}

For both ES-2 and ES-3 pellet samples, Raman spectra obtained from measurements on different macroscopic fragments of various sizes (from $\sim 10$ to $\sim 100 \mu \mathrm{m}$ ) (Pollock) or at different locations of the same fragment of the original pellets (Vermeer) are well-reproducible, the spectra can be found in Fig. S1 (supplementary information). Average spectra obtained by the two laboratories for both materials are given in Fig. 2. Wavenumbers of the bands detected and possible assignments are gathered in Table 6. A good agreement was obtained for bands univocally assigned to pure $\mathrm{UO}_{2}\left(445\right.$ and $1150 \mathrm{~cm}^{-1}$ ) by several authors [3-6, 8, 10, 11, 24-28] using lasers with wavelengths of 488, 514, 532 or $633 \mathrm{~nm}$. However, spectra obtained by Vermeer show peaks typical of strongly oxidized $\mathrm{UO}_{2}(2.09 \leq \mathrm{O} / \mathrm{U} \leq 2.20)$ in both samples [6]. These bands at 222, 337, $744 \mathrm{~cm}^{-1}$ were not observed by Pollock. This phenomenon might be due to sample oxidation by the laser, in accordance with the findings of Allen et al. [3]. But, measurements performed by Vermeer at the same spot during $30 \mathrm{~min}(30 \times 60 \mathrm{~s}$, total delivered power 

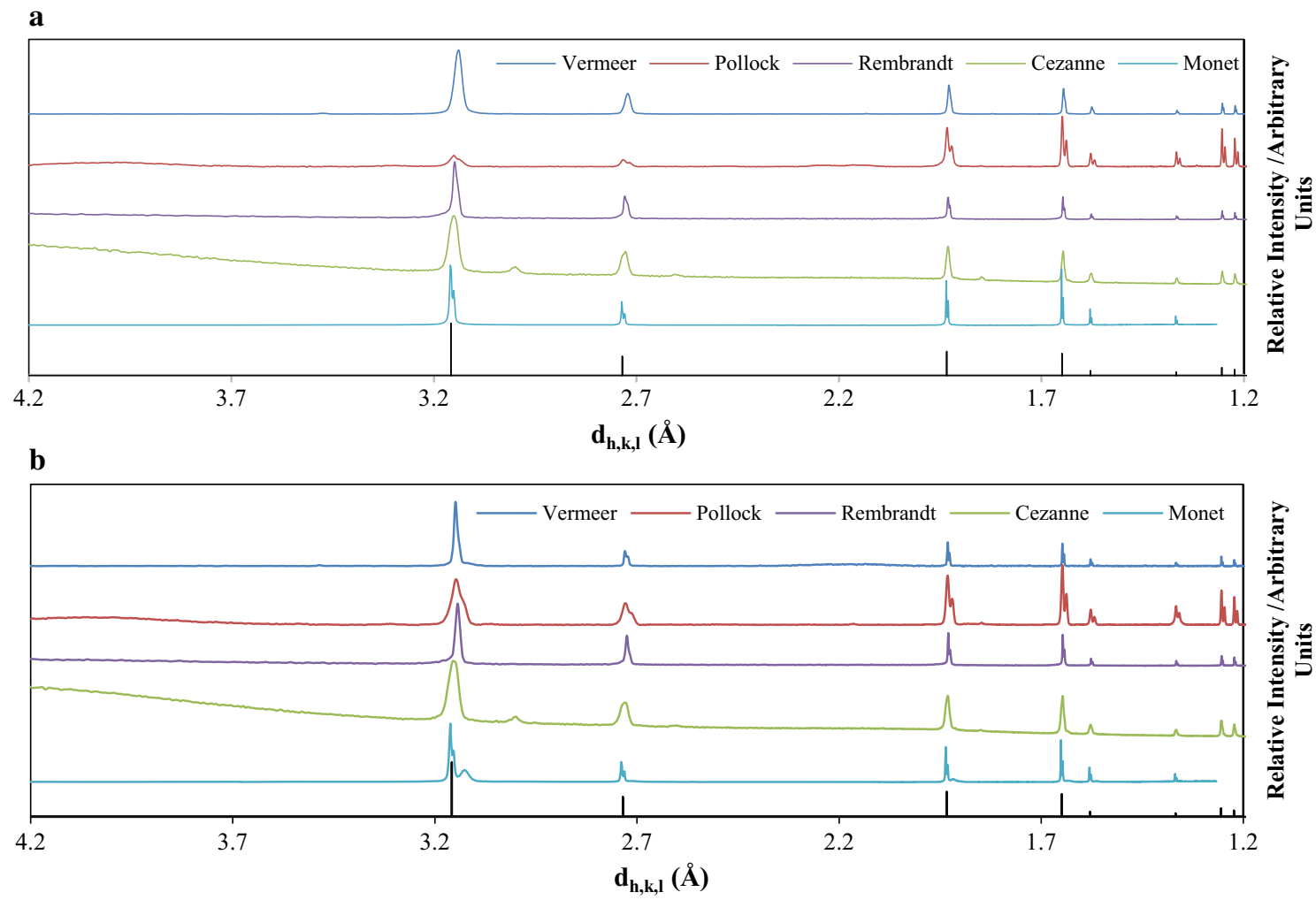

Fig. 1 From top to bottom, spectra for ES-2 (a) and ES-3 (b) obtained by XRD analysis of macroscopic samples by Vermeer, Pollock, Rembrandt, Cezanne, and Monet. The reference spectrum for $\mathrm{UO}_{2}$ has been added (black bars) at the bottom of the graph

of $\sim 13 \mathrm{~mW}$ ) for ES-3 show no significant change of the spectra along the experiment (see supplementary information Fig. S2). So these results suggest that the sample is not affected by the laser irradiation. As p-XRD analysis showed that the materials are pure $\mathrm{UO} 2$, another possible explanation lies in a surface oxidization phenomenon of the pellets for Vermeer. It might also be an artifact from the background subtraction due to high interferences from fluorescence. One way of avoiding such artifacts would be to perform analyses on raw spectra instead of background subtracted ones.

However, there is no evident difference between samples ES-2 and ES-3 that can be observed using $\mu$-RS.

\section{Pollock-RS results for the $\mu \mathrm{m}$-size particles sampled at the surfaces of the pellets}

As mentioned above, particle analyses were carried out by Pollock by $\mu$-RS on uranium particles sampled from the surfaces of the pellets by gently wiping the top of the pellets with a cotton cloth. Particles were then deposited on graphite disks. On each disk, 20 uranium-bearing particles were identified by SEM ("Quanta 3D”, FEI, Eindhoven, The Netherlands) with sizes ranging from 2 to $10 \mu \mathrm{m}$. Two categories of particles were evidenced by SEM imaging: (i) single "all-in-one-block" particles with typical size, (ii) agglomerates of sub- $\mu \mathrm{m}$-size particles embedded in a nondefinite matrix.

All Raman analysis of the all-in-one-block particles of both samples ES-2 and ES-3 led to neat spectra, obviously characteristic of $\mathrm{UO}_{2}$ (see Fig. 3) and similar to the ones obtained from macroscopic fragments of the pellets. Analyses were much more difficult for agglomerates, due to difficulty in focusing the laser beam onto sub- $\mu \mathrm{m}$ objects, the low amounts of uranium contained into individual sub-particles, and a very high background, most likely due to fluorescence. No other explanation was found to explain such background. Its origin probably lies in the matter in which uranium particles were embedded. As a result, Raman analyses were unsuccessful for a few agglomerates. For the other agglomerates, only the band at $\sim 1150 \mathrm{~cm}^{-1}$, which is the most intense one of the $\mathrm{UO}_{2}$ spectrum with the $514 \mathrm{~nm}$-laser, was detected (Fig. 3).

The conclusion is that the chemical composition of the particles sampled at the surface of the two pellets ES-2 and ES-3 are similar to the bulk composition of the two pellets (i.e., $\mathrm{UO}_{2}$ ) evidenced by the same laboratory (Pollock) with the same $\mu$-RS instrument and analytical conditions. 

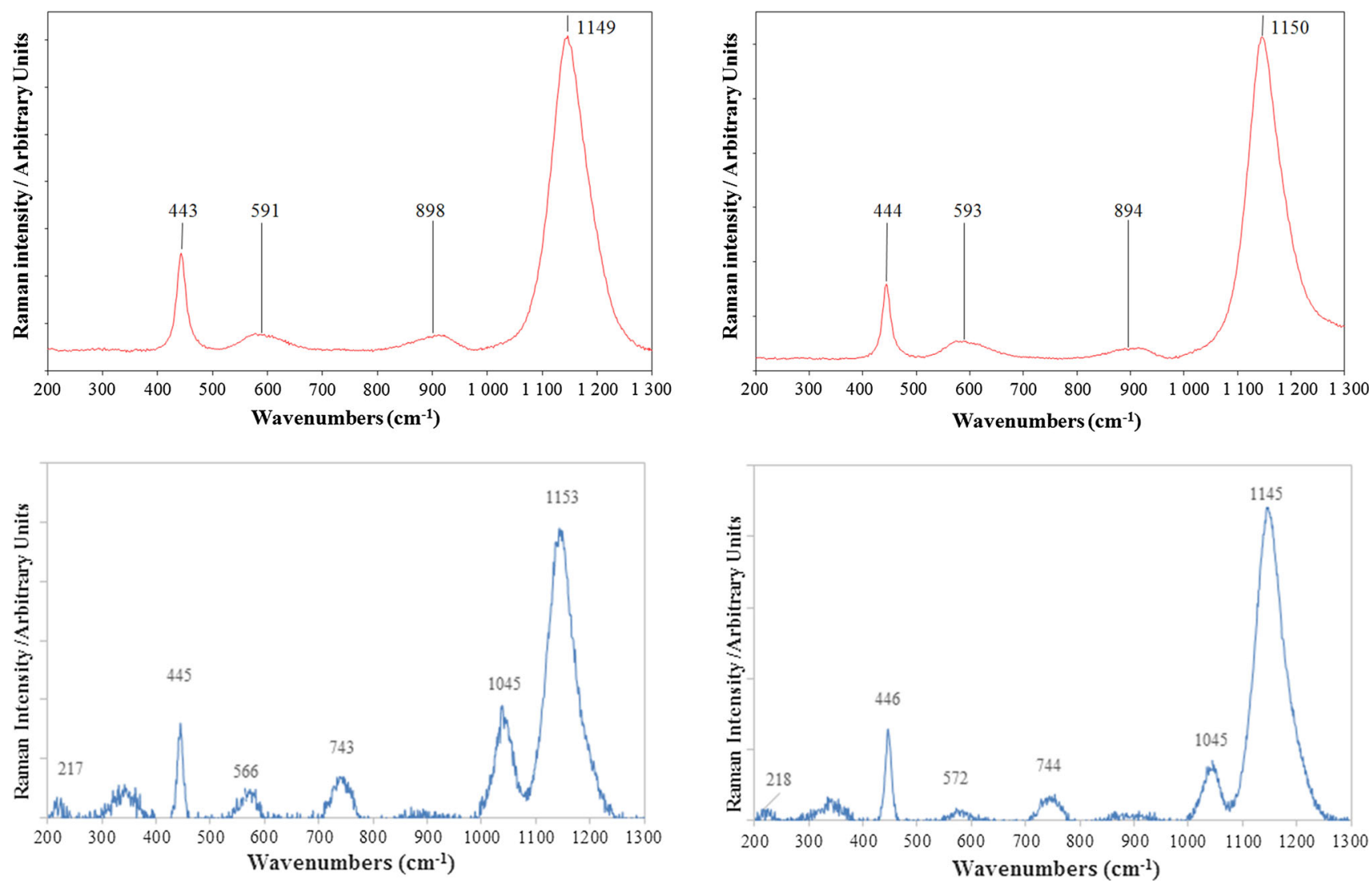

Fig. 2 Average spectra obtained at Pollock by $\mu$-RS analysis of 20 small fragments of the sample ES-2 (upper left) and ES-3 (upper right) and at Vermeer by $\mu$-RS analysis of ES-2 (lower left) and ES-3 (lower right)

\section{Results for the powder sample}

\section{XRD results for the powder material}

The XRD pattern obtained for the powder sample (ES-1) by the five laboratories are given in Fig. 4. The multi-phase diffraction pattern was highly complex. Some laboratories found it difficult to assign phases to the diffraction pattern due to its complexity and the presence of a large amorphous "hump" at low angle (high lattice plane spacing, $\left.d_{h, k, l}\right)$. The amorphous signal was attributed to the use of a plastic dome sample holder. By comparing the $d_{h, k, l}$ with positions referenced by the ICDD, the following compounds are detected: $\alpha-\mathrm{U}_{3} \mathrm{O}_{8}$, centered-face orthorhombic crystal phase (PDF card number 00-031-1424, dark gray bars [29]); $\beta-\mathrm{U}_{3} \mathrm{O}_{7}$, quadratic crystal phase (PDF card number 00-042-1215, light gray bars [30]) and $\mathrm{UO}_{2}$, centered-face cubic crystal phase (PDF card number 03-0650285, black bars [23]). With these data it is possible to say that the crystallographic structure of ES-1 differs from the one of ES-2 and ES-3. ES-1 has been identified as a mixture of different uranium oxides, $\mathrm{U}_{3} \mathrm{O}_{8}, \mathrm{U}_{3} \mathrm{O}_{7}$, and $\mathrm{UO}_{2}$. It is also possible that the peaks observed in the spectra might originate from another intermediate species of uranium oxide e.g., $\beta-\mathrm{U}_{64} \mathrm{O}_{143}\left(\mathrm{UO}_{2}+x\right.$ where $x=0.23$, PFD card 04-009-6397 [31] $)$ or $\mathrm{U}_{64} \mathrm{O}_{36}\left(\sim \mathrm{UO}_{1,75}\right.$, PDF card 04-006-7446 [32]) because the crystalline structures of these phases are quite similar it is difficult to draw any definitive conclusions regarding this intermediate species.

\section{ND results for the powder material}

ND results for ES-1 are given in Fig. 5, compared with the p-XRD results obtained by Rembrandt. The combined p-XRD and ND patterns confirm the presence of the three phases $\mathrm{UO}_{2}, \mathrm{U}_{3} \mathrm{O}_{8}$ and $\mathrm{U}_{3} \mathrm{O}_{7}$ in ES-1.

\section{$\mu$-RS results for the powder material}

According to observation performed with optical and electronic microscopes, ES-1 is composed of micrometersized and mm- sized particles. According to a visual observation by Pollock, with the optical microscope attached to the RS, sizes of the particles analyzed by RS were between $\sim 1$ and $\sim 5 \mu \mathrm{m}$. The Pollock analysis, although a $\mu$-RS with a thin spot size was employed, may measure more than one particle in each analyzed spot because sampled particles were very close to each other. 
Table 6 Main Raman bands detected by Pollock and Vermeer for samples ES-2 and ES-3 in the $200-1300 \mathrm{~cm}^{-1}$ range. Uncertainties are expanded uncertainties $(k=2)$. Peaks that were not identified by the software but are visible after background correction have not been assigned an uncertainty. Wavenumber are expressed in $\mathrm{cm}^{-1}$. Bands mentioned in this table are detected for all of the 20 measurements carried out by each laboratory

\begin{tabular}{|c|c|c|c|}
\hline $\begin{array}{l}\text { Sample } \\
\text { ID }\end{array}$ & $\begin{array}{l}\text { Pollock: band } \\
\text { wavenumber } \pm \text { uncertainty }\end{array}$ & $\begin{array}{l}\text { Vermeer: band } \\
\text { wavenumber } \pm \text { uncertainty }\end{array}$ & Possible assignment and reported range of wavenumbers \\
\hline \multirow[t]{8}{*}{ ES-2 } & & $217 \pm 6$ & Not assigned but observed by some authors for $\mathrm{U}_{3} \mathrm{O}_{8}^{\mathrm{a}}$ \\
\hline & & 337 & $\mathrm{U}_{3} \mathrm{O}_{8} \mathrm{~A}_{1 \mathrm{~g}} \mathrm{O}-\mathrm{U}$ stretching bands ${ }^{\mathrm{a}}$ \\
\hline & $443 \pm 2$ & $445 \pm 3$ & $\mathrm{UO}_{2}\left(\mathrm{U}-\mathrm{O}\right.$ stretching $\left.\mathrm{T}_{2 \mathrm{~g}}\right)$, range $445-450 \mathrm{~cm}^{-1}$ \\
\hline & $591 \pm 4$ & $566 \pm 8$ & $\mathrm{UO}_{2}$ (1LO phonons of the crystal), range $498-575 \mathrm{~cm}^{-1}$ \\
\hline & & $743 \pm 7$ & $\begin{array}{l}\mathrm{U}_{3} \mathrm{O}_{8} \text { combination of two } \mathrm{A}_{1 \mathrm{~g}} \mathrm{O}-\mathrm{U} \text { stretching bands, range } \\
\quad 751-763 \mathrm{~cm}^{-1}\end{array}$ \\
\hline & $898 \pm 3$ & 896 & Not assigned but often observed for $\mathrm{UO}_{2}$ \\
\hline & & $1047 \pm 6$ & \\
\hline & $1149 \pm 2$ & $1144 \pm 7$ & $\mathrm{UO}_{2}\left(2 \mathrm{LO}\right.$ phonons of the crystal), range $1149-1160 \mathrm{~cm}^{-1}$ \\
\hline \multirow[t]{8}{*}{ ES-3 } & & $218 \pm 7$ & Not assigned but observed by some authors for $\mathrm{U}_{3} \mathrm{O}_{8}^{\mathrm{a}}$ \\
\hline & & 337 & $\mathrm{U}_{3} \mathrm{O}_{8} \mathrm{~A}_{1 \mathrm{~g}} \mathrm{O}-\mathrm{U}$ stretching bands $\mathrm{a}^{\mathrm{a}}$ \\
\hline & $445 \pm 1$ & $446 \pm 3$ & $\mathrm{UO}_{2}\left(\mathrm{U}-\mathrm{O}\right.$ stretching $\left.\mathrm{T}_{2 \mathrm{~g}}\right)$, range $445-450 \mathrm{~cm}^{-1}$ \\
\hline & $593 \pm 5$ & $572 \pm 8$ & $\mathrm{UO}_{2}\left(1 \mathrm{LO}\right.$ phonons of the crystal), range $575-498 \mathrm{~cm}^{-1}$ \\
\hline & & $744 \pm 9$ & $\begin{array}{l}\mathrm{U}_{3} \mathrm{O}_{8} \text { combination of two } \mathrm{A}_{1 \mathrm{~g}} \mathrm{O}-\mathrm{U} \text { stretching bands, range } \\
\quad 751-763 \mathrm{~cm}^{-1}\end{array}$ \\
\hline & $894 \pm 3$ & 896 & Not assigned but often observed for $\mathrm{UO}_{2}$ \\
\hline & & $1045 \pm 7$ & \\
\hline & $1150 \pm 1$ & $1153 \pm 13$ & $\mathrm{UO}_{2}$ (2LO phonons of the crystal), range $1149-1160 \mathrm{~cm}^{-1}$ \\
\hline
\end{tabular}

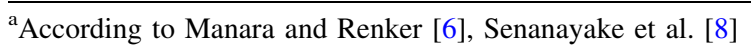

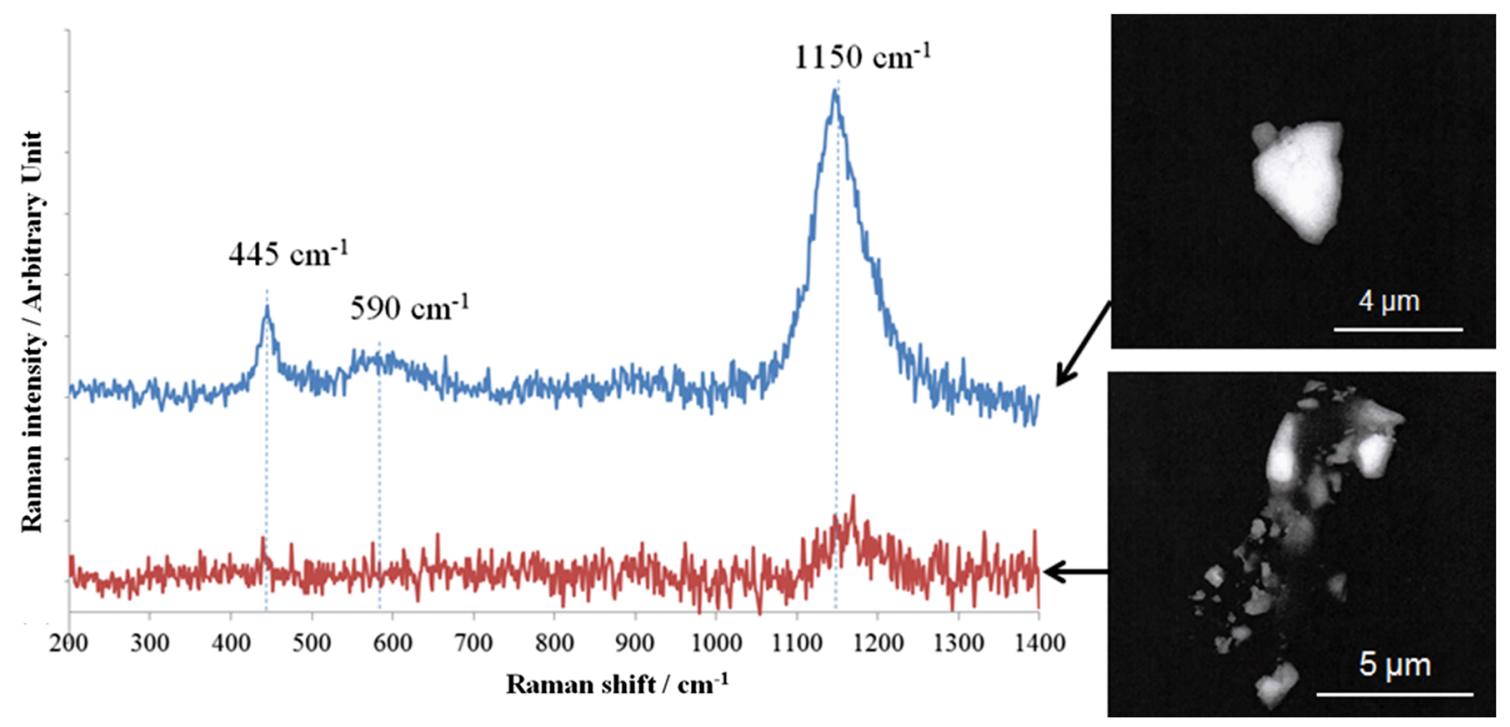

Fig. 3 Typical examples of Raman spectra obtained at Pollock for an all-in-one-block particle (upper blue spectrum and associated SEM image) and for an agglomerate of sub-micrometric particles (lower

Detected Raman bands and their proposed assignments are listed in Table 7. The Raman spectra obtained by the two laboratories for all of the 20 analyses can be seen in the supplementary information (Fig. S3). red spectrum and associated SEM image). Both particles were sampled at the surface of the ES-3 pellet

Most of the detected Raman bands for ES1 are typical bands commonly assigned to $\mathrm{U}_{3} \mathrm{O}_{8}$, in the range 233-241 cm $\mathrm{cm}^{-1} \quad[3, \quad 8-11, \quad 25], \quad 336-351 \mathrm{~cm}^{-1}$ $[3,5,8-11,25], 405-412 \mathrm{~cm}^{-1}[3,5,8-11,25]$, 


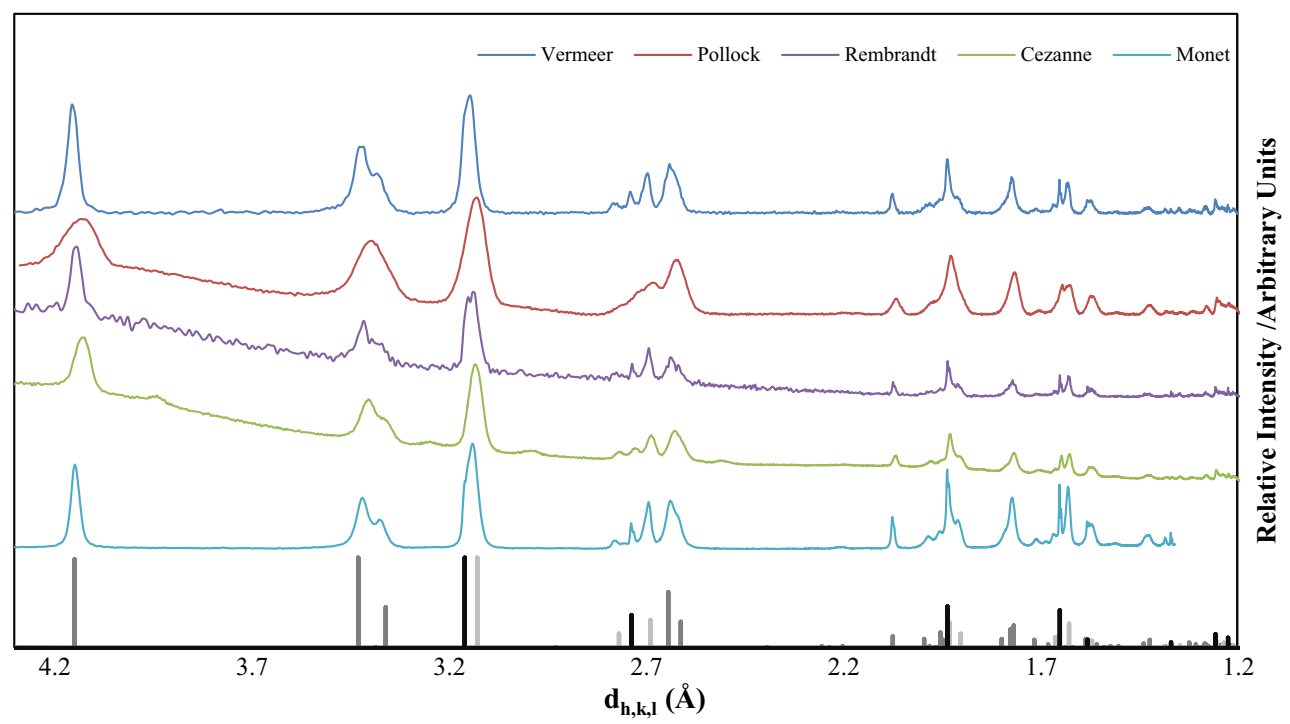

Fig. 4 From top to bottom, spectra obtained by XRD analysis of the sample ES-1 by Vermeer, Pollock, Rembrandt, Cezanne and Monet. At the bottom of the figure reference diffraction pattern for $\mathrm{U}_{3} \mathrm{O}_{8}$ (dark gray), $\mathrm{U}_{3} \mathrm{O}_{7}$ (light gray) and $\mathrm{UO}_{2}$ (black) are provided

Fig. 5 Comparison of ND and p-XRD patterns of ES-1 measured by Rembrandt. Orange crosses correspond to peaks of $\mathrm{UO}_{2}(\mathrm{PDF}-03-065-$ 0285 [24]), blue crosses correspond to peaks of $\mathrm{U}_{3} \mathrm{O}_{8}$ (PDF-01-074-2101 [33]) and green crosses correspond to peaks of $\mathrm{U}_{3} \mathrm{O}_{7}$ (PDF-00-0421215 [27]). (Color figure online)

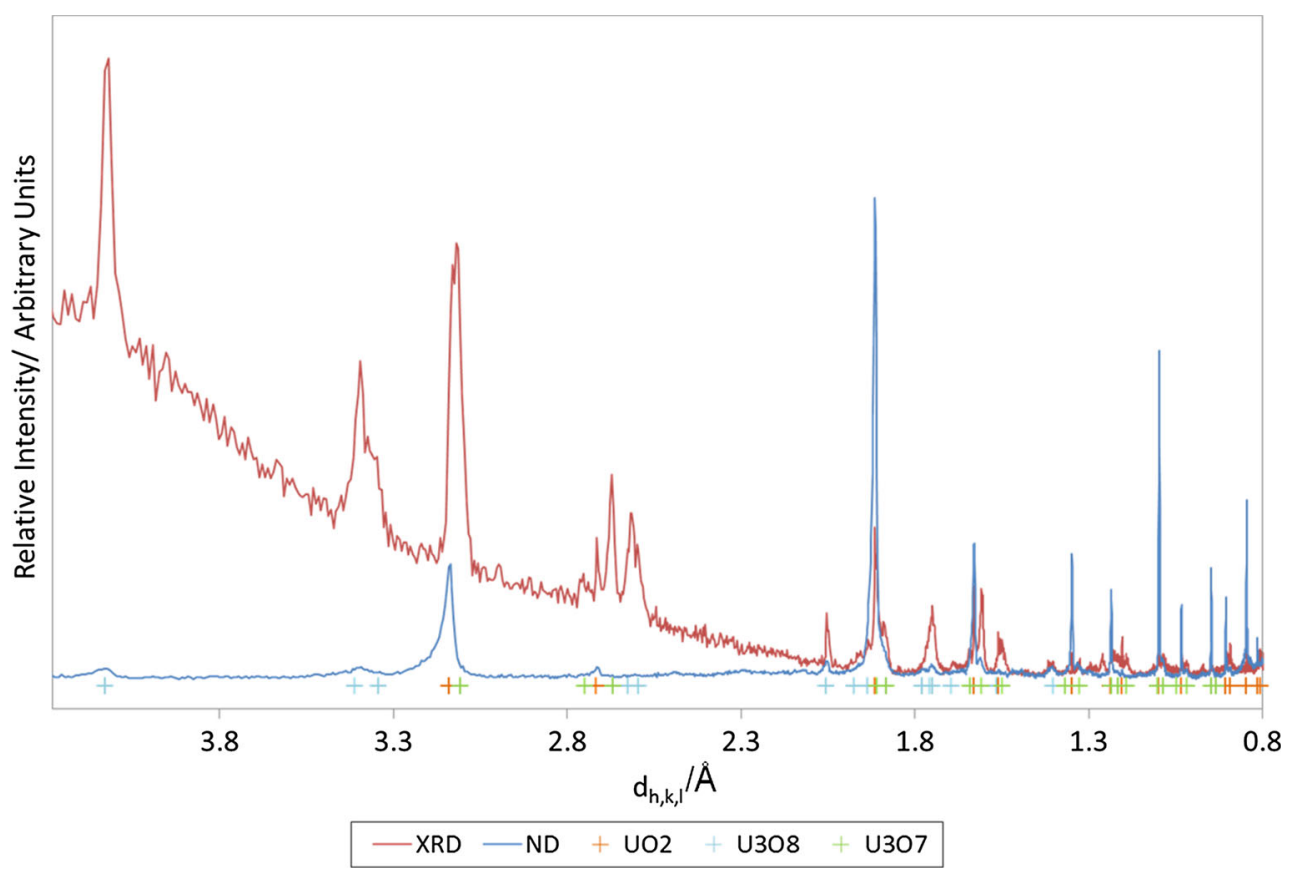

$638-640 \mathrm{~cm}^{-1}[3,9], 738-753 \mathrm{~cm}^{-1}[3,5,8,9,11,25]$, and 798-811 $\mathrm{cm}^{-1}[3,5,9-11,25]$. It should be noted that Raman bands at approximately $233-640 \mathrm{~cm}^{-1}$ and approximately $650-900 \mathrm{~cm}^{-1}$ are overlapping in most of the $\mu$-Raman spectra obtained at Vermeer and it is therefore difficult to assign bands in this region.

Furthermore, the main band commonly assigned to $\mathrm{UO}_{2}$ (at $\sim 450 \mathrm{~cm}^{-1}$ ) is also systematically detected by Pollock and it is visible as part of overlapping Raman bands for this region in $\mu$-RS from Vermeer. It should be noted that the very intense peak observed at $\sim 1150 \mathrm{~cm}^{-1}$ for the two
$\mathrm{UO}_{2}$ pellets is no longer observed in the case of ES-1 as this band corresponds to a phonon vibration of pure and homogeneous well-crystallized $\mathrm{UO}_{2}$ material.

Another band detected at $499 \pm 6 \mathrm{~cm}^{-1}$ by Pollock is close to a medium-intensity band, observed in the literature $[3,5,8-11,25]$ in the range $474-493 \mathrm{~cm}^{-1}$ for $\mathrm{U}_{3} \mathrm{O}_{8}$ (U-O stretching $\mathrm{E}_{\mathbf{g}}$ ), and was then initially assigned to $\mathrm{U}_{3} \mathrm{O}_{8}$. Raman analysis of $\mathrm{U}_{3} \mathrm{O}_{7}$ is poorly documented in the literature. Allen et al. [3] provide a reference spectrum for $\beta$ $\mathrm{U}_{3} \mathrm{O}_{7}$ with a characteristic band at $\sim 500 \mathrm{~cm}^{-1}$. Unfortunately, this spectrum has a poor resolution, so that this band 
Table 7 Main Raman bands for the sample ES-1 in the $200-1300 \mathrm{~cm}^{-1}$ range detected by Pollock and Vermeer. Uncertainties are expanded uncertainties $(k=2)$. Peaks that were not identified by the software but are visible after background correction have not been assigned an uncertainty. Wavenumber are expressed in $\mathrm{cm}^{-1}$

\begin{tabular}{|c|c|c|}
\hline $\begin{array}{l}\text { Pollock: band wavenumber } \pm \text { uncertainty } \\
\text { (rate of detection) }\end{array}$ & $\begin{array}{l}\text { Vermeer: band wavenumber } \pm \text { uncertainty } \\
\text { (rate of detection) }\end{array}$ & $\begin{array}{l}\text { Possible assignment and reported range of } \\
\text { wavenumbers }\end{array}$ \\
\hline $239 \pm 4(19 / 20)$ & $230 \pm 3(17 / 20)$ & $\begin{array}{l}\mathrm{U}_{3} \mathrm{O}_{8} \text { (vibration not assigned), range } \\
230-241 \mathrm{~cm}^{-1}\end{array}$ \\
\hline $330 \pm 6(19 / 20)$ & $336 \pm 17(18 / 20)$ & $\mathrm{U}_{3} \mathrm{O}_{8}\left(\mathrm{U}-\mathrm{O}\right.$ stretching $\mathrm{A}_{1 \mathrm{~g}}$ ) range $336-351 \mathrm{~cm}^{-1}$, \\
\hline $372 \pm 6(15 / 20)$ & 378 & Not assigned \\
\hline $417 \pm 4(20 / 20)$ & & $\mathrm{U}_{3} \mathrm{O}_{8}\left(\mathrm{U}-\mathrm{O}\right.$ stretching $\left.\mathrm{A}_{1 \mathrm{~g}}\right)$, range $405-412 \mathrm{~cm}^{-1}$ \\
\hline $454 \pm 5(20 / 20)$ & 451 & $\mathrm{UO}_{2}\left(\mathrm{U}-\mathrm{O}\right.$ stretching $\left.\mathrm{T}_{2 \mathrm{~g}}\right)$, range $445-450 \mathrm{~cm}^{-1}$ \\
\hline $499 \pm 6(20 / 20)$ & & $\mathrm{U}_{3} \mathrm{O}_{8}\left(\mathrm{U}-\mathrm{O}\right.$ stretching $\left.\mathrm{E}_{\mathrm{g}}\right)$, range $474-493 \mathrm{~cm}^{-1}$ \\
\hline $587 \pm 2(5 / 20)$ & & $\mathrm{UO}_{2}$ (vibration not assigned), range $575-498 \mathrm{~cm}^{-1}$ \\
\hline $646 \pm 7(20 / 20)$ & 612 & $\begin{array}{l}\mathrm{U}_{3} \mathrm{O}_{8} \text { (overtones of } \mathrm{U}-\mathrm{O} \text { stretching } \mathrm{A}_{1 \mathrm{~g}} \text { and } \mathrm{E}_{\mathrm{g}} \text { ), } \\
\text { range } 638-640 \mathrm{~cm}^{-1}\end{array}$ \\
\hline $742 \pm 3(16 / 20)$ & $760 \pm 10(18 / 20)$ & $\begin{array}{l}\mathrm{U}_{3} \mathrm{O}_{8}(\mathrm{U}-\mathrm{O}-\mathrm{U}-\mathrm{O} \text { stretching }) \text {, range } \\
738-753 \mathrm{~cm}^{-1}\end{array}$ \\
\hline $804 \pm 3(17 / 20)$ & & $\begin{array}{l}\mathrm{U}_{3} \mathrm{O}_{8} \text { (overtones of } \mathrm{U}-\mathrm{O} \text { stretching } \mathrm{A}_{1 \mathrm{~g}} \text { and } \mathrm{E}_{\mathrm{g}} \text { ), } \\
\text { range } 798-811 \mathrm{~cm}^{-1}\end{array}$ \\
\hline
\end{tabular}

is very close to the $\mathrm{U}_{3} \mathrm{O}_{8}$ bands in the $474-493 \mathrm{~cm}^{-1}$ region. So the shoulder detected at $499 \pm 6 \mathrm{~cm}^{-1}$ by Pollock can be attributed either to $\mathrm{U}_{3} \mathrm{O}_{8}$ or to $\mathrm{U}_{3} \mathrm{O}_{7}$. More generally, Raman spectra of $\mathrm{U}_{3} \mathrm{O}_{8}$ and of the intermediate species $\mathrm{U}_{3} \mathrm{O}_{7}$ and $\mathrm{U}_{4} \mathrm{O}_{9}$ show too much likeness to be distinguished due to the low-resolution in the $\mu$-RS spectra obtained at the $\mu \mathrm{m}$ scale.

However, significant differences for ES-1 were observed between the spectra obtained by the two laboratories. This can be seen in the average spectra given in Fig. 6. More precisely, some bands detected by Pollock are not observed by Vermeer, like the bands at $\sim 417, \sim 499$, and $\sim 804 \mathrm{~cm}^{-1}$. This is rather surprising as these bands are among the most frequent and most intense (especially a band at $\sim 410 \mathrm{~cm}^{-1}$ ) detected for $\mathrm{U}_{3} \mathrm{O}_{8}$. However, both laboratories, independently drew the conclusion that ES-1 is made of a mixture of $\mathrm{UO}_{2}$ and $\mathrm{U}_{3} \mathrm{O}_{8}$, as enough bands assigned to the two species were detected for all analyzed particles.

Regarding reproducibility of the spectra, all spectra from Vermeer appear to be similar and are visually wellreproducible. On the contrary, Pollock spectra show significant visual differences even if most of the bands are detected in all of the spectra, especially the bands usually assigned to $\mathrm{U}_{3} \mathrm{O}_{8}$. Actually, relative intensities of the detected bands are highly variable from one analyzed spot to the other. It should be mentioned that, due to the small size and uneven surface of the analyzed objects, bands are very broad and determination of the band position is not achieved with a good reproducibility and accuracy. This
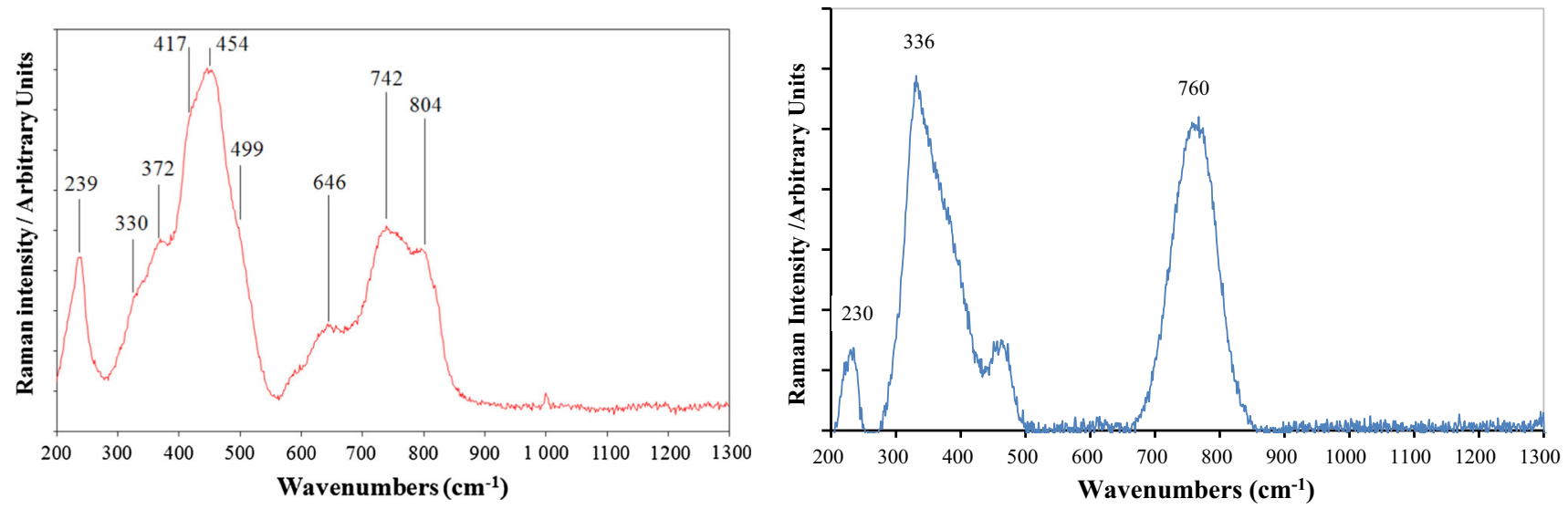

Fig. 6 Average Raman spectra obtained by Pollock (left) and by Vermeer (right) for the sample ES-1 
lack of reproducibility might also be due to sample inhomogeneity at the particle's level. The better reproducibility of the Vermeer spectra may be due to a larger spot size, which leads to the analyses of a higher amount of material, and thus, of more homogeneous micro-samples.

The literature suggests that the presence of $\mathrm{U}_{3} \mathrm{O}_{8}$ may result from a partial oxidization of $\mathrm{UO}_{2}$ after moderate heating under the laser beam $[3,8,11]$. However, detection of the same significant proportion of $\mathrm{U}_{3} \mathrm{O}_{8}$ with very low laser power invalidates this hypothesis.

\section{Discussion}

\section{Comparison between results obtained by $\mu-R S$ and $p-X R D$}

Regarding the pellet samples (ES-2 and ES-3), $\mu$-RS results obtained by Pollock are in very good agreement with results provided by $\mathrm{p}$-XRD analysis. Results obtained by Vermeer are slightly biased towards an oxidized uranium oxide, probably due to difficulties in background subtraction or accidental surface oxidation.

Regarding the powder sample (ES-1), $\mu$-RS results obtained by both Vermeer and Pollock are in good agreement with $\mathrm{p}$-XRD results, as analyses with both techniques show that the ES-1 sample is made of a mixture of $\mathrm{UO}_{2}$ and $\mathrm{U}_{3} \mathrm{O}_{8}$. Powder XRD analysis by Pollock also revealed the possible presence of the $\beta-\mathrm{U}_{3} \mathrm{O}_{7}$ phase, which was not observed using $\mu$-RS. It was not identified as $\beta-\mathrm{U}_{3} \mathrm{O}_{7}$ mainly because the Raman spectrum of $\beta-\mathrm{U}_{3} \mathrm{O}_{7}$ is not welldescribed in the literature. But when revisiting the results after the XRD analysis, the $499 \pm 1 \mathrm{~cm}^{-1}$ band is significantly closer to the band for $\beta-\mathrm{U}_{3} \mathrm{O}_{7}-500 \mathrm{~cm}^{-1}$ as reported by Allan et al. [3] - than that of $\mathrm{U}_{3} \mathrm{O}_{8}$. However, the Raman spectra obtained from particulate material have had a poor quality (low signal-to-noise ratio and broad bands) so it was difficult to draw any conclusions on the presence of another phase from this peak alone.

However, both techniques give complementary information. RS provides information essentially related to the surface of the sample, whereas p-XRD gives the chemical phase of the bulk material. Also, $\mu$-RS requires a significantly lower amount of material than p-XRD; an analysis can be carried out on a $\mu \mathrm{m}$-sized particle. Important to note is that there are XRD techniques available that are able to measure small amounts of sample, but these require a different kind of instrumentation. For example, it is possible to measure single particles using $\mu$-XRD. But because $\mu$-XRD requires a highly focused incident beam, which can be obtained at a synchrotron, for example, it is hardly standard instrumentation in any laboratory [34-36]. Surface and bulk information will normally be concordant if the sample is broken and the analysis by $\mu$-RS is performed on enough (here 20 analyses for each sample) randomly chosen spots on a face representative of the inner material (which does not undergo surface oxidization). Also, the micrometric spatial resolution of $\mu$-RS allows studying the homogeneity of the sample at a micrometer scale. Additionally, great care must be taken in sample preparation of the samples to avoid any chemical modification of the sample surface (i.e., oxidization or reduction by means of chemical reagents or thermal treatment). This means that $\mu$-RS must be performed directly and as quickly as possible on the materials, or the samples must be stored in an environment that does not affect their chemistry.

\section{Comparison of results obtained by ND and XRD measurements at Rembrandt}

ND produced a superior high-angle diffraction pattern relative to $\mathrm{p}-\mathrm{XRD}$, which assisted in confirming oxidized phases. The high angle peaks of the ND pattern were more resolved and higher in intensity than those from $\mathrm{p}-\mathrm{XRD}$, making them more amenable to successful refinement, if the data were collected at the right conditions, to determine weight fractions of the different phases present.

The sealed vanadium sample holder used for ND was transparent to neutrons, and did not contribute to the pattern as well as satisfied the safety requirements.

ND is less likely to be easily accessible to nuclear forensics laboratories than $\mathrm{p}$-XRD; however, the results obtained by Rembrandt show that if it is available, ND can be a complementary technique to $\mathrm{p}$-XRD. ND could be most useful in situations where a superior higher-angle diffraction pattern is required, sample preparation requirements of $\mathrm{p}-\mathrm{XRD}$ are likely to induce artefacts in the diffraction pattern, or the $\mathrm{p}$-XRD pattern is unlikely to be of sufficient quality to be amenable to quantitative analysis.

\section{Contribution to the determination of the origin of the materials}

Findings of the p-XRD and $\mu$-RS analyses suggest that, unlike samples ES-2 and ES-3, which exhibit the same $\mathrm{UO}_{2}$ phase, the ES-1 (powder) is an oxidized sample. The data suggested that an oxidation process (e.g., by heating) had been initiated, turning $\mathrm{UO}_{2}-\mathrm{U}_{3} \mathrm{O}_{8}$. Moreover, an incomplete oxidation process would explain the different phases identified by $\mathrm{p}-\mathrm{XRD}$ and $\mu$-RS.

\section{Conclusion and perspectives}

This paper shows that $\mu$-RS, XRD and ND techniques provided useful and coherent information on chemical phases present in three nuclear materials, two objects which looked like nuclear fuel pellets and one powder, in 
the framework of an international exercise on nuclear forensics. Results of all three techniques were in good agreement: similar phases were detected even if $\mu$-RS is performed on significantly lower amounts of samples. This work demonstrated that $\mu$-RS can be used as a highly effective screening tool in nuclear forensics. It reliably detects the various discreet phases present in uranium oxide samples. In a more general sense, $\mu$-RS and XRD can be regarded as complementary techniques for in-depth nuclear forensic analyses. On the one hand, $\mu$-RS is fast and easy to implement. It requires only minute amount of material; has the capability to identify chemical phases even in amorphous materials; ans allows the study of homogeneity at the $\mu \mathrm{m}$-level, for $\mu$-RS; and analysis of specific micrometric details. RS provides information related to the surface of the samples because of its limited depth penetration into uranium oxides. In contrast, XRD allows quantification of the various chemical phases present in the material and, thanks to the analysis of a larger amount of sample, provides representative information of the bulk composition of the studied material. $\mu$-RS data can be used to complement or substitute for XRD analysis, as long as caution is used when drawing conclusions from the data seeing as $\mu$-RS does not penetrate as deep into the sample. The complementary nature of XRD and ND can assist in positive identification of intermediate phases and potentially the accurate determination of weight fractions of phases present in nuclear forensic samples. In the near future, these techniques will certainly be used in forthcoming nuclear forensic exercises, carried out on other types of samples. So the laboratories will gain more experience and knowledge within their respective capabilities whether it be $\mu$-RS, XRD or ND, for identification of chemical phases in seized nuclear materials.

Acknowledgements The authors would like to thank the following people for their contribution to the results: Marcus Hedman (Chalmers University of Technology, Sweden); Sonia JeandemangeDjaoud, Pierre Pagat, Jean-Claude Thomas and Basile Morisse (CEA, DAM, DIF, France); and Grant Griffiths and Andrew Wotherspoon (ANSTO, Australia). NECSA would like to acknowledge the general support received from the NECSA Nuclear Obligations Management Services Department of South Africa and the financial support from the U.S. Department of State, which made it possible for NECSA to participate in the ETG data review meeting in Karlsruhe, Germany and the important ITWG-20 annual meeting in Budapest, Hungary. The Lawrence Livermore National Laboratory analyses were performed under the auspices of the U.S. Department of Energy by Lawrence Livermore National Laboratory under Contract DE-AC52$07 N A 27344$.

Open Access This article is distributed under the terms of the Creative Commons Attribution 4.0 International License (http://crea tivecommons.org/licenses/by/4.0/), which permits unrestricted use, distribution, and reproduction in any medium, provided you give appropriate credit to the original author(s) and the source, provide a link to the Creative Commons license, and indicate if changes were made.

\section{References}

1. Schwantes JM, Marsden O (2015) Collaborative materials exercise after action report, PNNL-24410. Pacific Northwest National Laboratory, Richland

2. IAEA (2006) Nuclear Forensics Support, Technical Guidance Reference Manual Nuclear Security Series No.2. International Atomic Energy Agency, Vienna

3. Allen GC, Butler IS, Ahn Tuan N (1987) Characterisation of uranium oxides by micro-Raman spectroscopy. J Nucl Mater 144:17-19

4. Bruno J, Casas I, Puigdoménech I (1991) The kinetics of dissolution of $\mathrm{UO}_{2}$ under reducing conditions and the influence of an oxidized surface layer $\left(\mathrm{UO}_{2+x}\right)$ : application of a continuous flowthrough reactor. Geochim Cosmochim Acta 55(3):647-658

5. Palacios ML, Taylor SH (2000) Characterization of uranium oxides using in situ micro-raman spectroscopy. Appl Spectrosc 54(9):1372-1378

6. Manara D, Renker B (2003) Raman spectra of stoichiometric and hyperstoichiometric uranium dioxide. J Nucl Mater 321(2-3):233-237

7. Seikhaus WJ (2003) Composition of uranium oxide surface layers analyzed by m-Raman spectroscopy, UCRL-CONF-201179. MRS 2003 Fall Meeting, Boston

8. Senanayake SD, Rousseau R, Colegrave D, Idriss H (2005) The reaction of water on polycrystalline $\mathrm{UO}_{2}$ : pathways to surface and bulk oxidation. J Nucl Mater 342(1-3):179-187

9. Idriss H (2010) Surface reactions of uranium oxide powder, thin films and single crystals. Surf Sci Rep 65(3):67-109

10. Pointurier F, Marie O (2010) Identification of the chemical forms of uranium compounds in micrometer-size particles by means of micro-Raman spectrometry and scanning electron microscope. Spectrochim Acta, Part B 65(9-10):797-804

11. Jégou C, Caraballo R, Peuget S, Roudil D, Desgranges L, Magnin M (2010) Raman spectroscopy characterization of actinide oxides $\left(\mathrm{U}_{1-\mathrm{y}} \mathrm{Pu}_{\mathrm{y}}\right) \mathrm{O}_{2}$ : resistance to oxidation by the laser beam and examination of defects. J Nucl Mater 405:235-243

12. Eloirdi R, Ho Mer Lin D, Mayer K, Caciuffo R, Fanghänel T (2014) Investigation of ammonium diuranate calcination with high-temperature X-ray diffraction. J Mater Sci 49:8436-8443

13. Sweet LE, Blake TA, Henager CH, Hu S, Johnson TJ, Meier DE, Peper SM, Schwantes JM (2013) Investigation of the polymorphs and hydrolysis of uranium trioxide. J Radioanal Nucl Chem 296:105-110

14. Ho Mer Lin D, Manara D, Varga Z, Berlizov A, Fanghänel T, Mayer K (2013) Applicability of Raman spectroscopy as a tool in nuclear forensics for analysis of uranium ore concentrates. Radiochim Acta 101:779-784

15. Grazulis S, Chateigner D, Downs RT, Yokochi AFT, Quiros M, Lutterotti L, Manakova E, Butkus J, Moeck P, Le Bail A (2009) Crystallography open database-an open-access collection of crystal structures. J Appl Cryst 42(4):726-729

16. Gražulis S, Daškevič A, Merkys A, Chateigner D, Lutterotti L, Quirós M, Serebryanaya NR, Moeck P, Downs RT, LeBail A (2012) Crystallography Open Database (COD): an open-access collection of crystal structures and platform for world-wide collaboration. Nucleic Acids Res 40(Database Issue):D420-D427. https://doi.org/10.1093/nar/gkr900

17. Downs RT, Hall-Wallace M (2003) The American mineralogist crystal structure database. Am Miner 88(1):247-250 
18. Tandon L, Kuhn K, Martinez P, Banar J, Walker L, Hahn T, Beddingfield D, Porterfield D, Myers S, LaMont S, Schwartz D, Gallimore D, Garner S, Spencer K, Townsend L, Volz H, Gritzo R, McCabe R, Pereyra R, Peterson D, Scott M, Ruggiero C, Decker D, Wong A (2009) Establishing reactor operations from uranium targets used for the production of plutonium. J Radioanal Nucl Chem 282:573-579

19. Delegard CH, Sinkov SI, Chenault JW, Schmidt AJ, Welsh TL, Pool KN (2014) Determination of uranium metal concentration in irradiated fuel storage basin sludge using selective dissolution. J Radioanal Nucl Chem 299(3):1871-1882

20. Liss K-D, Hunter BA, Hagen ME, Noakes TJ, Kennedy SJ (2006) Echidna-the new high-resolution powder diffractometer being built at OPAL. Phys B 385-386(part2):1010-1012

21. Black DR, Windowver DA, Mendenhall MH, Henins A, Filliben JJ, Cline JP (2015) Certification of standard reference material 1976b. Powder Diffr. https://doi.org/10.1017/ S0885715615000445

22. Zhang ZM, Chen S, Liang YZ, Liu ZX, Zhang QM, Ding LX, Ye F, Zhou H (2010) An intelligent background-correction algorithm for highly fluorescent samples in Raman spectroscopy. J Raman Spectrosc 41(6):659-669

23. Clausen K, Hayes W, Macdonald JE, Schnabel P, Hutchings MT, Kjems JK (1983) Neutron scattering investigation of disorder in UO2 and ThO2 at high temperatures. High Temp High Press 15(4):383-390

24. Graves PR (1990) Raman microprobe spectroscopy of uranium dioxide single crystals and ion implanted polycrystals. Appl Spectrosc 44:1665-1667

25. Stefaniak EA, Alsecz A, Sajo IE, Worobiec A, Mathé Z, Török S, Van Grieken R (2008) Recognition of uranium oxides in soil particulate matter by means of $\mu$-Raman spectrometry. $\mathrm{J}$ Nucl Mat 381(3):278-283

26. He H, Ding Z, Shoesmith DW (2009) The determination of electrochemical reactivity and sustainability on individual hyper- stoichiometric $\mathrm{UO}_{2+\mathrm{x}}$ grains by Raman microspectroscopy and scanning electrochemical microscopy. Electrochem Com 11(8):1724-1727

27. Desgranges L, Baldinozzi G, Simon P, Guimbretière G, Canizarès A (2012) Raman spectrum of $\mathrm{U}_{4} \mathrm{O}_{9}$ : a new interpretation of damage lines in $\mathrm{UO}_{2}$. J Raman Spectrosc 43(3):455-458

28. Canizarès A, Guimbretière G, Tobon YA, Raimboux N, Omnée R, Perdicakis M, Mueau B, Léoni E, Alam MS, Mendès E, Simon D, Matzen G, Corbel C, Barthe MF, Simon P (2012) In situ Raman monitoring of materials under irradiation: study of uranium dioxide alteration by water radiolysis. J Raman Spectrosc 43(10):1492-1497

29. Smith D et al (1979) ICDD Grant-in-Aid. Pennsylvania State University, Pennsylvania

30. Tempest PA, Tucker PM, Tyler JW (1988) J Nucl Mater 151(3):269-274

31. Willis BTM (1964) Structures of $\mathrm{UO}_{2}, \mathrm{UO}_{2+\mathrm{x}}$ and $\mathrm{U}_{4} \mathrm{O}_{9}$ by neutron diffraction. J de Phys 25(5):431-439

32. Nakayama Y (1971) A phase study on the tie line of $\mathrm{U}_{3} \mathrm{O}_{7} \mathrm{PuO}_{2}$. J Inorg Nucl Chem 33:4077-4084

33. Ackermann RJ, Chang AT, Sorrell CA (1977) Thermal expansion and phase transformations of the $\mathrm{U}_{3} \mathrm{O}_{8-z}$ phase in air. $\mathrm{J}$ Inorg Nucl Chem 39:75-85

34. Degueldre C, Martin M, Kuri G, Grolimund D, Borca C (2011) Plutonium-uranium mixed oxide characterization by coupling micro-X-ray diffraction and absorption investigations. $\mathrm{J}$ Nucl Mater 416(1-2):142-150

35. Singer DM, Zachara JM, Brown GE Jr (2009) Uranium speciation as a function of depth in contaminated hanford sediments - a micro-xrf, micro-xrd, and micro- and bulk-xafs studey. Environ Sci Technol 43(3):630-636

36. Salbu B, Janssens K, Lind OC, Proost K, Gijsels L, Danesi PR (2004) Oxidation states of uranium in depleted uranium particles from Kuwait. J Environ Radioact 78:125-135 